\title{
Philosophiques
}

\section{Marcel Hénaff, Claude Lévi-Strauss, Paris, Éditions Pierre Belfond, (Coll. « Les Dossiers Belfond »), 1991, 435 pages.}

\section{Sylvain Pinard}

Volume 20, numéro 1, printemps 1993

URI : https://id.erudit.org/iderudit/027220ar

DOI : https://doi.org/10.7202/027220ar

Aller au sommaire du numéro

Éditeur(s)

Société de philosophie du Québec

ISSN

0316-2923 (imprimé)

1492-1391 (numérique)

Découvrir la revue

Citer ce compte rendu

Pinard, S. (1993). Compte rendu de [Marcel Hénaff, Claude Lévi-Strauss, Paris, Éditions Pierre Belfond, (Coll. « Les Dossiers Belfond »), 1991, 435 pages.]

Philosophiques, 20(1), 224-228. https://doi.org/10.7202/027220ar d'utilisation que vous pouvez consulter en ligne.

https://apropos.erudit.org/fr/usagers/politique-dutilisation/ 
Marcel Hénaff, Claude Lévi-Strauss, Paris, Éditions Pierre Belfond, (Coll. "Les Dossiers Belfond"), 1991, 435 pages.

\section{par Sylvain Pinard}

De tout temps, Claude Lévi-Strauss s'est défendu de faire œuvre de philosophie. Il a certes proposé moult développements de type philosophique, élaborant des concepts utiles à son approche structuraliste ou répondant directement à des philosophes comme Sartre, Ricœur ou Freud. Jamais pourtant Lévi-Strauss n'a tenté de systématiser toute son entreprise scientifique ou de faire la généalogie des concepts qu'il a utilisés, se repliant plutôt sur un instrumentalisme inspiré de la phonologie qui prône une méthode d'analyse structuraliste. Néanmoins, comme Lévi-Strauss a débordé le strict dialogue avec les tenants des disciplines connexes à l'anthropologie pour s'adresser aux philosophes, le Claude Lévi-Strauss de Marcel Hénaff est d'un intérêt indéniable pour ces derniers. En refusant la spéculation philosophique, le structuralisme devient de fait une expérience de l'altérité.

En effet, au fil des données empiriques, Lévi-Strauss a dû admettre l'hypothèse d'un « esprit humain » universel, défini de manière inductive et assurant une communication transculturelle; il a aussi posé l'hypothèse d'un «inconscient», ou encore celle d'une « pensée symbolique », autant de concepts qui appellent une certaine explicitation. Marcel Hénaff nous propose un « exposé critique » de la pensée lévi-straussienne que nous pourrions qualifier de conciliant et il s'applique, au cours de l'exposition généalogique de 
l'œuvre, à en résoudre les obscurités et les contresens. Manifestement, $M$. Hénaff a lı Lèvi-Strauss, ce que peu de gens peuvent revendiquer : il déplie avec brio les thèmes anthropologiques familiers de dépaysement de l'ethnologue (accueillir, penser l'Autre), d'interdiction de l'inceste, de principe de réciprocité (vs l'échangisme maxxiste), de structures de parentè, des mythes, du totémisme, des rites, de l'art et de l'histoire, tout cela à la lumière des hypothèses conceptuelles mentionnées ci-haut. Ce faisant, $M$. Henaff pointe les limites du structuralisme lévi-straussien. Nous avons alors sous les yeux un exposé éclairant. révélateur mêne, où le plus grand ethnologue français est abondamment et pertinemment cité. Le livre reste ainsi abordable tant aux non-initiés au structuralisme qu'aux initiés à la recherche d'un regard rafraichissant sur les thèses souvent mal comprises que Lévi-Strauss a défendues contre les penseurs de son temps. Cependant. on peut regretter que l'auteur ne nomme pas assez les interlocuteurs en dialogue avec Lévi-Strauss, auxquels, au long de ses interprétations, il répond implicitement de façon si méticuleuse.

Plus spécifiquement, des dix chapitres de la première partie, cinq nous semblent susceptibles d'intéresser davantage le chercheur en pliilosophie. Le chapitre IV, intitulè « Catégories inconscientes et universalite de l'esprit », présente « le coeur de la position philosophique de Lévi-Strauss », à savoir «l'hypothèse d'un répertoire de possibilités inconscientes, existant en nombre fini et dont l'actualisation dans l'evénement est fonction d'un critère de compatibilité réciproque » (p. in8). Hénaff explique que nous devons tirer le structuralisme de Lévi-Strauss vers un leibnizianisme sans entendement divin plutôt que vers un kantisme sans sujet transcendantal, tel que Riçeur le soutenait. En effet. loin d'être issu d'une déduction transcendantale, ce répertoire de possibilités inconscientes est établi à partir d'un strict programme d'observations. L'esprit humain agit le plus souvent inconsciemment mais c'est un inconscient sans contenu, sorte de forme vide qui organise, qui impose des lois de structure. Cet esprit agit soit par dispositif symbolique au sein des cultures snuvages, soit de façon explicite par l'entremise de la science occidentale. Par conséquent, Lévi-Strauss a le mérite d'avoir attribuer le même statut symbolique aux schèmes composant la socièté, c'est-à-dire les schèmes cosmologiques, logiques, scientifiques, moraux, esthétiques, sociologiques, technologiques. économiques, sensoriels, météorologiques et astronomiques. Quant à savoir pourquoi l'esprit s'éprouve ainsi dans les mythes où, de façon privilégiée, ces divers schèmes s'entr'expriment (p. rg8), Lévi-Strauss se refuse de spéculer et s'arrête à la formule de constat « tout se passe comme si » (p. i 17). Plus qu'à un finalisme ou à un fonctionnalisme, c'est donc à un constat empirique d'une certaine contrainte interne que nous avons affaire (p. $8 \mathrm{~s}$ ).

«La pensée symbolique » (chapitre V) continue de développer la «psychologie » (au sens classique) cognitiviste de Lévi-Strauss en mettant en scène quatre problèmes particuliers, tels : a) la propriété inductive du symbolisme et le passage de l'individuel au collectif ; b) le symbolisme comme culture; c) le symbolisme comme système débouchant sur une socio-logique; d) les rapports entre symbolisme, codes et science. Le symbolisme s'avère un concept essentiel pour cerner la pensée de Lévi-Strauss, « non seulement pour comprendre les données anthropologiques mais aussi parce qu'il engage toute une perspective sur la nature du social, d'une part, et sur l'universalité des caté- 
gories logiques, d'autre part, autrement dit, sur la nature de l'esprit humain » (p. I2g). De la propriété inductive du symbolisme de ses premiers écrits, nous observons le passage à une assimilation de plus en plus intine des manifestations culturelles et symboliques; ce faisant. l'explication de Lévi-Strauss se démarque des positions maturalistes utilitaristes et fonctionnalistes pour leur opposer une « théorie symbolique de la société » (p. 135).

Dès qu'il y a société lıumaine, dès qu'une expérience subjective est faite, elles s'inscrivent dans la médiation symbolique qui est performance (rite. panure), dispositif opératoire inscrit au sein du social. Le symbolisme a le statut paradoxal d'ètre de la culture qu'il institue par convention tout en ètant, par sa factualité, de l'universalité de la nature. Le symbolisme fait système, il ordonne à partir des éléments sensibles ; il s'avère un dispositif dont l'intelligibilité dépend du caractère différentiel et oppositionnel des éléments en jeu. c'est-i-dire de l'identification non pas des ressemblances mais des invariants. Ce repérage des invariants, thème cher à l'antlıropologie structurale, nous incline à appeler « langage » les systèmes de parenté, de rituels, de mythes. En conférant au signifié inconnu une signification indéterminee, la pensée symbolique se démarque de la science par l'usage d'un « signifiant flottant» (p. 144), un signifiant qui peut faire flecche de tout bois et qui renvoie à cette sorte de «bricolage » intellectuel typique de la culture sauvage (p. I55).

Le chapitre VIII, « La leçon de l'œuvte d'art », intéressera surtout les chercheurs en esthètique par la présentation synthétique des rapports entre structuralisme et arts visuels modernes et contemporains. En particulier, nous voyons expliciter certaines attaques contre l'impressionnisme et le cubisme, signes d'excès de culture de la modernité. Lévi-Strauss soutient que la fonction de l'art est cognitive en manifestant les propriétés de l'objet, ce qui confère à l'œuvre une certaine objectivité. L'opposition clé pour comprendre l'art de façon critique s'avère être celle entre signifier et représenter, opposition qui renvoie selon Hénaff à deux sens différents de la mimésis : signifier, le premier sens de mimésis, se réfère à une production au sens aristotélicien, alors que représenter, c'est-à-dire imiter, figurer, relève plutòt de l'idéalisme de Platon (p. 207). Quoi qu'il en soit, nous reconnaissons le leibnizianisme que l'« on val |... retrouver dans ce rapport d'entr'expression de l'art et de la sociétè » (p. 20g). rapport qui, à défaut de n'être ni dans l'impressionnisme ni dans le cubisme, entraîne la condamnation de ces derniers courants artistiques.

Le délicat problème des limites de l'explication historique fait l'objet du chapitre IX, « Le temps des sociétés et la question de l'histoire ». Les articulations entre histoire et système, structure et événement, sociétés du « refus de l'histoire » et sociétés « historiques», permettent de définir les éléments d'une « histoire structurale ». Cette dernière épithète semble paradoxale considérant les traditionnels reproches d'oblitération du diachronique adressés au structuralisme. Mais comme la méthode structurale se penche justement sur des objets où le diachronique est minimal, ces reproches s'évanouissent, d'autant plus que cette méthode collige précieusement ce qui subsiste de diachronique dans ces sociétés sauvages sans écriture. 11 faut donc tenir compte des bribes du diachronique, mais pour vérifier les lois de structure mises à jour dans le synchironique : 
Pourtant le structuraliste [...] prétend atteindre une universalite, et si Lévi-Strauss ne parle pas de nature humaine, il ne cesse de se référer à un esprit humain dont les lois seraient constantes dans l'espace et dans le temps. Mais précisément cette universalité ne porte ni sur des besoins ni sur des contenus (p. 22g).

De cette manière, le structuralisme disqualifie ou dépasse les systèmes théoriques d'Eliade, de Jung et de Freud en recherchant non pas des formes substantivées mais des catégories, des principes, des structures. Du même coup. l'idéologie historiciste d'autolégitimation de la culture occidentale s'en trouve d'autant minée car, de toute façon,

I...] la possibilité même de l'histoire [dans la société sauvagel est sans cesse interceptée par le système. Tout ce qui arrive est immédiatement codé dans le dispositif spatial des homologies nature/culture. En ce sens l'histoire n'a pas lieu. La structure annule d'avance l'événement (p. 237).

Par contre, le structuralisme ne peut déterminer pourquoi telle valeur est en vigueur à tel endroit et récusée à tel autre.

Dans le chapitre offert en conclusion à la première partie, "Remarques pour conclure : la question morale $»$, Hénaff présente les prolégomènes lévi-straussiens d'une éthique du vivant qui englobe l'humanisme étroit défendu par la charte des droits et libertés de l'homme. Cette éthique du vivant, promue au rang d'impératif catégorique, dénonce l'exclusion des autres espèces vivantes du statut moral réservé uniquement à l'homme. En ce sens, il nous semble que l'épithète de « naturalisme » que Tzvetan Todorov (Nous et les autres, Paris, Seuil, 1989, p. 89) appose aux positions éthiques de Lévi-Strauss convienne mieux que celle d'humanisme. D’autre part, Lévi-Strauss rejoint les humanistes français en s'élevant contre la destruction des cultures sauvages, et il valorise, il réhabilite ces dernières en montrant qu'au fond, elles ne diffèrent pas de la nôtre, malgré les apparences : trop souvent, nous sommes victimes des préjugés évolutionniste et continuiste et d'ethnocentrisme (p. 40). Les cultures sauvages ne savent peut-être pas qu'elles pensent, comme disait Ricœur, mais, ajouterait Lévi-Strauss, néanmoins elles pensent (p. I6g). C'est pour cette raison qu'on doit préférer l'épithète « sauvage » à celle de "primitif » pour désigner ces sociétés autres. La même humanité, la même moralité caractérisent tant les Occidentaux que les Sauvages, car c'est le même esprit humain qui se joue par les mécanismes symboliques. Cette dimension morale de la pensée lévi-straussienne a souvent échappé à ses détracteurs :

Le travail de réflexion, produit à la rencontre de plusieurs sociétés, en faisant varier les perspectives, donne un accès pragmatique à une universalitè qui n'a rien d'idéal, mais qui aboutit à déterminer de manière plausible le mode de vie qui peut convenir au mieux à l'espèce humaine (p. 37).

Ce mode de vie, ce nouvel humanisme tendant à un universalisme, LéviStrauss l'institue pourtant au niveau de la différence à reconnaître entre groupes humains et même à maintenir, face à l'universalisme abstrait des droits de l'homme qui le déterritorialise, le coupe de sa culture. Au danger d'un relativisme culturel absolu, Hénaff met en relief que Lévi-Strauss lui a opposé le principe d'une coalition nécessaire des cultures : « c'est leur fécondation réciproque qui les rend aptes à se développer et à survivre » (p. 25I); mais il s'agit surtout d'établir la bonne distance entre les cultures pour qu'elles coexis tent sans être assimilées. Cette menace d'homogénéisation des cultures n'est 
cependant, comme Todorov le relève (op.cit., p. 92), jamais prouvée, et la disparition des sociétés sauvages dépendrait peut-ètre plus de l'urbanisation que des chocs culturels.

A cette première partie s'adjoint un riche « Parcours de l'œuvre » qui présente des compte rendus de vingt-six écrits majeurs de lévi-Strauss. Le chercheur se félicitera d'y trouver entre autres le détail et la mise en contexte des références et citations parsemant le texte qui précède, tout comme il aimera parcourir le cas échéant la « Chronologie » et la « Bibliographie »très fournies qui complètent le volume.

Département de philosophie

College André-Grasset 